\title{
Low-cost adsorbents for urban stormwater pollution control
}

\author{
Yang Deng (凶) \\ Department of Earth and Environmental Studies, Montclair State University, Montclair, NJ 07043, USA
}

\begin{abstract}
H I G H L I G H T S
- Various low-cost adsorbents are studied for capturing urban stormwater pollutants.

- Adsorbents are selected based on both pollutant adsorption and unexpected leaching.

- Application modes of adsorbents influence their utilization efficacy in practice.
\end{abstract}

\section{A R T I C L E I N F O}

\section{Article history:}

Received 11 January 2020

Revised 10 May 2020

Accepted 10 May 2020

Available online 12 June 2020

\section{Keywords:}

Urban stormwater

Runoff pollutants

Low-cost adsorbents

Adsorption

Chemical leaching

\author{
G R A P H I C A B S R A C T
}

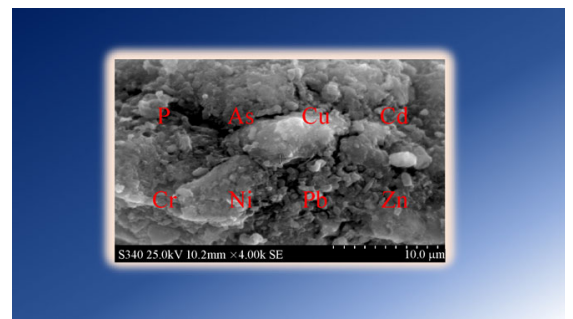

\begin{abstract}
A B S T R A C T
Stormwater represents a major non-point pollution source at an urban environment. To improve the treatment efficacy of stormwater infrastructure, low-cost adsorbents have increasingly gained attention over the past decades. This article aims to briefly discuss several key aspects and principles for utilization of low-cost adsorbents for urban stormwater treatment. To determine whether a low-cost adsorbent is suitable for stormwater treatment, two aspects should be carefully assessed, including: 1) its adsorption mechanisms and behaviors that can influence the binding strength, adsorption kinetics, and treatment capacity; and 2) unwanted chemical leaching patterns that can affect the extent of water quality degradation. Furthermore, the application mode of an adsorbent in the system design influences the utilization efficiency. Adsorbents, after dosed to soil media in infrastructure, would eventually become ineffective after oversaturation. In contrast, standalone filters or innovative composite adsorbents (e.g., adsorbent-coated mulch chips) can enable a long-lasting adsorption due to periodic replacement with fresh adsorbents. The aforementioned principles play a key role in the success of urban stormwater treatment with low-cost adsorbents.
\end{abstract}

(C) The Author(s) 2020. This article is published with open access at link.springer.com and journal.hep. com.cn

\section{Introduction}

Urban areas housed more than $55 \%$ of the world's population in 2018. By 2030, the fraction is projected to reach 60\% (United-Nations, 2018). Although urbanization brings many benefits, it causes various environmental issues. One such example is polluted urban stormwater, a major non-point pollution source at an urban setting. Different from rural areas, cities are characterized by a vast majority of "hard" surfaces, such as roads, sidewalks,

$\triangle$ Corresponding author

E-mail: dengy@mail.montclair.edu

Special Issue-Accounts of Aquatic Chemistry and Technology Research (Responsible Editors: Jinyong Liu, Haoran Wei \& Yin Wang) driveways, and parking lots, which are covered by different water-resistant materials (e.g., asphalt, concrete, brick, and stone). The resultant imperviousness up to $100 \%$ can greatly increase accumulations of various constituents from different sources during a dry period and lead to a high runoff flowrate at a precipitation event. Consequently, the increased runoff flow more readily flushes these pollutants on the imperviousness to contain more pollutants in urban runoff. Typical urban runoff pollutants include sediments, toxic heavy metals, synthetic organic pollutants (SOCs), nutrients, and pathogens (Makepeace et al., 1995; Chiew et al., 1997; Lee and Bang, 2000; Obropta and Kardos, 2007). They can contaminate soil and groundwater during infiltration through soil and surface water when runoff enters into receiving water bodies. Furthermore, these contaminants can foul drinking water 
sources, harm wildlife habitats, and make recreational water unsafe, thereby posing a serious threat to ecological and public health at city communities.

In the United States, early urban stormwater management aimed to rapidly reduce peak flows for prevention of flooding (NJDEP, 2004). Nonetheless, new strategies have emerged to encourage best management practices (BMPs) for simultaneously addressing both quantity and quality of urban stormwater (NRC, 2009). Particularly, special attention has been directed to low impact development (LID) techniques, a subset of BMPs. LID, such as bioretention basins, green roof, and grassed swales, utilizes small-sized and distributed treatment components to preserve or mimic the site's pre-developed hydrologic response to precipitation and allows for runoff infiltration (NJDEP, 2004).

To improve the efficiency of urban stormwater infrastructure, particularly LID systems, various adsorbents have been attempted for capturing different runoff pollutants. Among them, low-cost adsorbents have attracted more attention due to a low and even "free" price as well as the potential to achieve sustainable stormwater treatment designs. The objective of this Account article is to briefly discuss several key aspects and principles for utilization of low-cost adsorbents for urban stormwater treatment.

\section{Low-cost adsorbents for stormwater treatment}

A variety of low-cost adsorbents have been studied for urban stormwater treatment for capturing different runoff pollutants. Several examples are discussed as follows.

1) Biochar is a fine grained and highly porous charcoal created via a pyrolysis process, in which biomass is heated to high temperatures under low or no oxygen conditions (Lehmann and Joseph, 2015). Besides production of

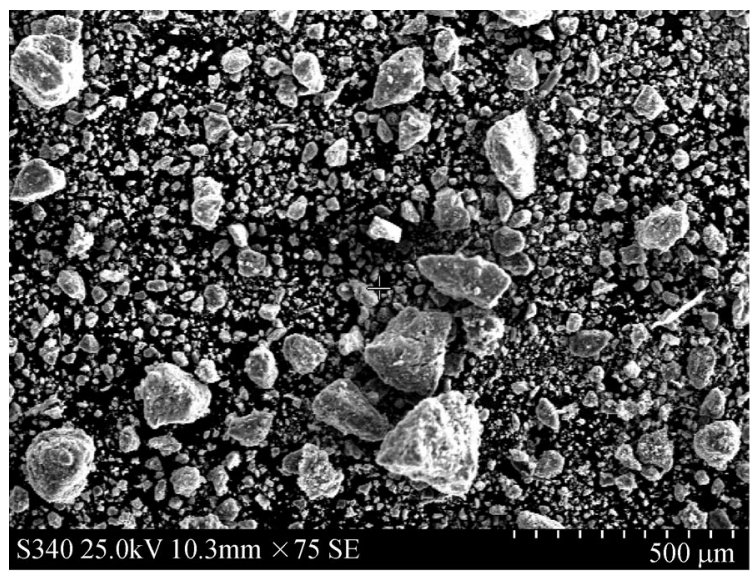

(a) renewable biomass energy and carbon sequestration for mitigation of climate change, biochar has been demonstrated as an excellent material for agronomic and environmental applications (Chan et al., 2007; Xie et al., 2015; Li et al., 2017). Dosed into stormwater filtration systems, biochar has proven for effective removal of multiple runoff pollutants such as toxic heavy metals (e.g., $\mathrm{Pb}$ and $\mathrm{Zn}$ ), nutrients (i.e., $\mathrm{N}$ and $\mathrm{P}$ ), SOCs (e.g., polycyclic aromatic hydrocarbons (PAHs)), trace organic contaminants (TOrCs), and pathogenic indicators (e.g., E. coli) (Mohanty and Boehm, 2014; Reddy et al., 2014a; Ulrich et al., 2015). Scanning electron microscopy (SEM) images of sewage sludge-derived biochar are shown in Fig. 1. As seen, the biochar particles have a broad range of particle sizes and a coarse surface with a high specific surface area.

2) Scrap tires have been long studied as an alternative sorbent for abating water pollutants (Knocke and Hemphill, 1981; Gunasekara et al., 2000). Previous studies demonstrate that they are capable of binding certain toxic metals and nutrients in stormwater (Wanielista and Chang, 2008; Deng et al., 2016).

3) Sawdust is a powdered by-product particles during woodworking operations (e.g., sawing and milling). It has a capability of sorbing toxic metals (e.g., Cd), different $\mathrm{N}$ species, and SOCs (e.g., PAHs) in stormwater (Semerjian, 2010; Harmayani, 2012; Björklund and Li, 2015).

4) Water treatment residual (WTR) is the settled sludge collected from sedimentation tanks at traditional water treatment plants. It is a water industry waste principally comprising aluminum ( $\mathrm{Al}$ ) or iron $(\mathrm{Fe})$ oxides and colloidal particles originally present in raw water. These metal oxides are the hydrolysis products of $\mathrm{Al}$ or Fe salts intentionally dosed during coagulation for destabilizing colloids in water. WTR has proven for improving the removals of heavy metals and phosphorus in urban stormwater (O'Neill and Davis, 2012a,b; Soleimanifar et al., 2016; Soleimanifar et al., 2019).

5) Zeolites are crystalline hydrated aluminosilicates with

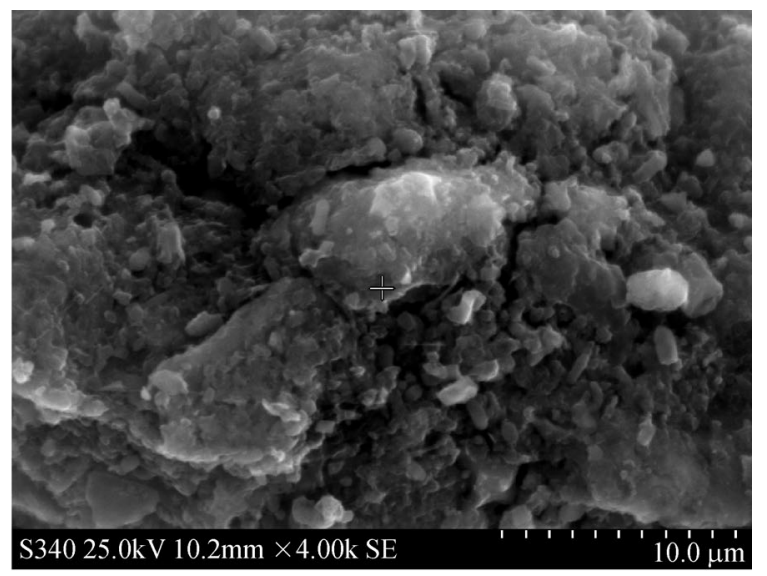

(b)

Fig. 1 SEM images of sewage sludge derived biochar at different scales (pyrolysis conditions: $600^{\circ} \mathrm{C}$ and $1 \mathrm{~h}$ ). 
a framework structure, having ion-exchange capacity and molecular sieve properties (Kesraoui-Ouki et al., 1994). When zeolites are used for stormwater treatment, they primarily target at the removal of heavy metals in stormwater (Pitcher et al., 2004; Wu and Zhou, 2009; Ziyath et al., 2011).

6) Iron filings are the byproduct of the grinding, filing, or milling of finished iron products. It exhibits an excellent capability for capturing different metals (e.g., Cr) and phosphate in stormwater (Erickson et al., 2012; Reddy et al., 2014b, c).

7) Fly ash is an industrial waste produced from the combustion of coal and other solid fuels for energy production (Zhang et al., 2008; Ahmaruzzaman, 2010). It exists typically in the form of small particles comprising various $\mathrm{Si}, \mathrm{Al}, \mathrm{Fe}$, and $\mathrm{Ca}$ minerals (Ahmaruzzaman, 2010). Fly ash has been reported for effective immobilization of phosphorus and heavy metals in stormwater (GencFuhrman et al., 2007; Zhang et al., 2008; Chavez et al., 2013; Duranceau and Biscardi, 2015). The binding of phosphorus with fly ash is irreversible (Zhang et al., 2008).

Of note, a specific low-cost adsorbent is mostly infeasible to effectively adsorb all the runoff pollutants of interest. To extend the adsorption capacity of an adsorbent for more contaminants of concern, surface modification is an approach. For example, aluminum (hydr)oxide can be impregnated into biochar for promoting the sorption of arsenate in stormwater (Liu et al., 2019). Nano zero-valent iron (ZVI) is integrated to oak sawdustderived biochar for highly efficient reduction of nitrobenzene (Wei et al., 2019). Another example is to fix ZVI on bentonite-fly ash pellets for removing $\mathrm{Cd}$ and $\mathrm{Pb}$ in water (Mwamulima et al., 2018). The approach allows for production of more adsorbents tailored to specific stormwater treatment goals. On the other hand, the pollutant removal can be enhanced through combination of adsorption with other treatment technologies. For example, dielectrophoresis was used to capture submicro-meter sized bentonite particles capable of adsorbing $\mathrm{Cd}^{2+}$ and $\mathrm{Pb}^{2+}$ in water (Jin et al., 2019)

Furthermore, part of the aforementioned low-cost adsorbents for stormwater treatment are themselves municipal or industrial solid wastes. For example, scrap tires account for approximately $2 \%$ of the USA municipal solid waste with an annual generation rate of 290 million (USEPA, 2020). And approximately two million tons of WTR are generated every year in the USA (Prakash and SenGupta, 2003), the most of which are disposed in landfills. Reuse of the "free" municipal or industrial waste can potentially further reduce operations and maintenance (O\&M) costs for the stormwater treatment and provide the "useless" waste a new life, making the system more economically competitive in the market and finding a sustainable approach to the waste originally disposed through traditional landfilling or incineration.

\section{Implications of adsorption mechanisms and behaviors}

Although this Account article does not aim to review the mechanisms governing the adsorption of low-cost adsorbents for runoff pollutants, the understanding of adsorption mechanisms and behaviors would provide essential information for the adsorbent application to stormwater treatment.

Fundamentals of low-cost adsorbents for capturing runoff pollutants rely heavily upon the adsorbent type, pollutant species, and reaction conditions. For example, complexation and electrostatic interactions are acknowledged as the major mechanisms for arsenic sorption to biochar (Li et al., 2017), while Al-based WTR adsorption of phosphate in runoff is principally ascribed to the innersphere surface complexation (Soleimanifar et al., 2019). Of note, the adsorption mechanism can significantly affect the binding strength between the adsorbents and pollutants. Typically, the formation of strong bindings, for example, inner-sphere surface complexation, enables an irreversible sorption and minimizes desorption of these pollutants sorbed on the adsorbents in practices. In contrast, physical adsorption or outer-sphere surface complexation leads to a relatively weak binding, so that pollutants likely desorb back to the bulk solution.

Adsorption patterns of low-cost adsorbents for urban runoff pollutants can be demonstrated through adsorption kinetic and isotherm tests through laboratory-scale batch studies. Key kinetics information such as reaction order and rate constants is essential to ensuing column studies and realistic engineering design. If the adsorption can not be instantly completed, the system design is kinetically controlled. That is, for a pollutant of concern, sufficient contact time between adsorbents and stormwater needs to be ensured to reach the target removal efficiency. If the adsorption can be immediately achieved, the pollutant concentration in treated stormwater is not mostly dependent of contact time, but relies upon the adsorption isotherm patterns. Under this situation, the system design is thermodynamically controlled. Moreover, the adsorption isotherm behaviors help determine the adsorption capacity of a certain quantity of adsorbents for a specific pollutant, which can be used to size a stormwater treatment reactor within an expected design lifetime.

Of note, solution chemistry conditions and co-existing runoff matrix constituents can largely influence the pollutant adsorption behaviors. Consequently, the adsorption results obtained at laboratory-controlled conditions frequently disagree with those at a realistic environment. Therefore, the factors affecting the adsorption process should be carefully evaluated, such as $\mathrm{pH}$, ionic strength, temperature, dissolved organic matter (e.g., natural organic matter (NOM) or soil organic matter), and common ions in runoff (e.g., chloride, sulfate, nitrate, phosphate, and 
bicarbonate). These factors may positively or negatively influence the removal of target pollutants. For example, a solution $\mathrm{pH}$ decrease leads to a more positively charged surface on biochar, thereby promoting the adsorption of $\operatorname{arsenic}(\mathrm{V})$, which primarily exists in the form of anions, to biochar due to the enhanced electrostatic attraction (Wang et al., 2015). On the other hand, the presence of NOM can inhibit the biochar immobilization of stormwater E. coli in a biofilter (Mohanty et al., 2014).

\section{Chemical leaching}

Although low-cost adsorbents are expected to remove runoff pollutants of interest, unexpected leaching from the adsorbents can occur. Leaching should be considered at two scenarios: 1) the release happens during service to degrade quality of the runoff after contact with these adsorbents; and 2) the leaching occurs after the spent adsorbents are collected and then disposed in landfills. Only the adsorbents with a minimal leaching potential can be considered for practical use ( $\mathrm{Li}$ et al., 2018). Although long-term pilot or field column studies can accurately determine the leaching potential of an adsorbent, the approach is seldom used due to an unfeasibly long experiment duration. Therefore, standardized leaching methods are frequently adopted for rapid estimation of chemical leaching from these adsorbents.

Traditionally, two standard leaching protocols, i.e., Synthetic Precipitation Leaching Procedure (SPLP) (EPA SW-846 Method 1312) and Toxicity Characteristic Leaching Procedure (TCLP) (EPA SW-846 Method 1311), are used to estimate the species and amounts of unwanted leaching chemicals at two different situations. SPLP is a standard EPA method to determine the leaching potential of adsorbents under a simulated exposure-to-rainfall environment, while the TCLP test simulates a typical municipal landfill condition to quantify chemical leaching from the waste and determines whether the waste can be disposed of as non-hazardous wastes in municipal landfills. Recently, USEPA has developed the new leaching protocol, Leaching Environmental Assessment Framework (LEAF) consisting of four leaching methods (Methods 1313-1316), data management tools, and scenario assessment approaches (USEPA, 2017). The four LEAF methods can be used individually or together to describe the release of inorganic constituents of potential concern for solid materials such as adsorbents. Particularly, the LEAF protocol can be used for estimation of environmental impacts of beneficial use of secondary materials. However, the LEAF method for the leaching of organic constituents remains under development (USEPA, 2017).

Released chemicals from the low-cost adsorbents likely consist of pollutants desorbed from the adsorbents or chemical species originally present in the adsorbent materials. For example, Cd(II) sorbed on sugarcane- straw-derived biochar was reported to desorb due to weak bindings (Melo et al., 2016), highlighting that adsorption mechanisms influence reliability of pollutant removal through adsorption. On the other hand, many undesirable chemicals may leach from the adsorbents themselves. When scrap tire rubber is adopted for stormwater treatment, $\mathrm{Zn}$ can be largely released (Deng et al., 2016), because $\mathrm{Zn}$ can account for $1 \%$ of tire-tread material on the basis of mass (Councell et al., 2004). The intrinsic limitation of scrap tire may prevent its acceptability in the stormwater treatment market. However, $\mathrm{Zn}$ leaching can be inhibited through combination of scrap tire with other adsorbents (e.g., WTR) (Deng et al., 2016).

When biochar is selected as an alternative adsorbent, the release of toxic organic compounds is a likely concern, such as dioxins (Hale et al., 2012) and PAHs (Hilber et al., 2012; Quilliam et al., 2013) that can be inherently formed from pyrolysis. Release of PAHs from sewage sludge based biochar was investigated (Chen et al., 2019). Leaching potential of 16 USEPA PAHs increases with the increase in the biochar pyrolysis temperature with an opposite pyrolytic temperature dependence with their concentrations in solid biochar. The PAH leaching appears to be related to the release of hydrophobic organic compounds (HOCs) in biochar, which can create a mobile phase to facilitate the mobilization of PAHs to water, as well as the leaching of certain metals such as $\mathrm{Ca}$ and $\mathrm{Al}$ (Chen et al., 2019).

Special attention should be paid to dissolution of adsorbent materials, which may occur at an acidic environment or through chemical reduction. Such dissolution can lead to the release of both sorbed pollutants and elements originally present in adsorbent materials. For example, iron-based materials have been intensively studied for adsorption of heavy metals and phosphate in stormwater primarily through the complexation reactions of these pollutants and iron (hydr)oxides (Wu and Zhou, 2009; Erickson et al., 2012; Norris et al., 2013; Reddy et al., 2014a). However, Fe(III) in the iron (hydr)oxides tends to be reduced to more soluble $\mathrm{Fe}(\mathrm{II})$ at an anoxic condition, which is common when the adsorbents are dosed into the soil media during stormwater treatment (Nagar et al., 2010). Consequently, the dissolution of ironbased adsorbents causes the release of iron and sorbed contaminants.

\section{Treatment system with low-cost adsorbents}

Adsorption with the low-cost adsorbents for stormwater pollutants is a heterogeneous reaction. It should be noted that adsorption kinetics and isotherm data are obtained from batch tests in the most studies, while column studies are mostly used to examine the treatment performance of the adsorbents at the conditions related to a realistic 
stormwater treatment environment. The two different reactors have different hydraulic and mixing characteristics. Batch reactors are operated in a completely mixing state without the flow input or output. In contrast, the column studies are achieved in a packed-bed down flow reactor with a nearly plug flow state as well as continuous flow input and output.

In practices, application of low-cost adsorbents to urban stormwater treatment can be integrated into various infrastructure. Two common application modes include: 1) that adsorbents are directly dosed into the soil media in green infrastructure (e.g., biofiltration systems and bioswales) (O’Neill and Davis, 2012a,b; Liu and Davis, 2013; Tian et al., 2019); and 2) that adsorbents are used as filter media alone or together with others in stormwater filters (e.g., roof downspout filters and filter socks). A key difference between the two application modes is whether adsorbents are left on site after their service.

At the first scenario, low-cost adsorbents are directly dosed as a soil amendment. Once the adsorbent is oversaturated with certain pollutants, the adsorption eventually becomes ineffective. Therefore, the application mode can not provide a long-lasting treatment. Moreover, the spent adsorbents would be left on site. Further addition of the adsorbent into soil for maintaining the adsorption capability is not practical, particularly for metal-based adsorbents (e.g., WTR and iron fillings) that may lead to excessive accumulation of metals in soil. In contrast, standalone filter systems at the second application mode are a better option. With appropriate operations and maintenance, the stormwater treatment systems can provide a long-standing treatment on condition that the adsorbents can be timely replaced before oversaturation.

A recent application mode is the utilization of adsorbentcoated wood mulch (Soleimanifar et al., 2016; Soleimanifar et al., 2019). Mulching is a common and beneficial practice for landscaping and agriculture. One of the widely used mulches is wood chips used as a protective layer spread on the top of soil. Such mulch chips have been widely used in green infrastructure. Their primary purposes include protection of the soil from erosion, moisture conservation, and weed control (Turgeon et al., 2009). Although wood chips are reported to capture certain metals from stormwater (Jang et al., 2005; Jang et al., 2007), they are not comparable with other low-cost adsorbents (e.g., WTR) in terms of adsorption capacity reported in literature (Chiang et al., 2012). However, to coat more effective adsorbent materials on the wood mulch chips can develop new low-cost adsorbents for stormwater treatment. The low-cost adsorbent coated mulch can remain the basic functions of common wood mulch chips, while having the improved adsorption capability for runoff pollutants. The new filter media can be employed in combination with green infrastructure or used independently. Like common wood mulch, they require annual replacement, mostly in the spring, thereby enabling a long-term stormwater treatment provided that the replacement with fresh coated mulch chips can be implemented before oversaturation of the old ones. This new attempt can potentially transform traditional landscape mulching into a technically viable and economically affordable stormwater treatment option.

\section{Conclusions}

Low-cost adsorbents have received considerable attention for alleviating stormwater pollution at an urban setting. Two aspects need to be carefully evaluated to determine whether a low-cost adsorbent is suitable for application to urban stormwater treatment. One is the understanding of mechanisms and behaviors of the adsorption reactions between the adsorbents and runoff pollutants of interest. Because solution chemistry conditions and co-existing solutes can influence the adsorption patterns, key factors affecting the adsorption effects should be cautiously assessed at field-related conditions. Information regarding the binding strength, sorption kinetics, and treatment capacity would build a basis for ensuing treatment system design. The other aspect is to identify and quantify unexpectedly leaching chemical species from the adsorbents at different scenarios. Significant release of unwanted chemicals from adsorbents during their service can degrade quality of treated stormwater and thus prevent their adoption in practices. Different from the sorbents for municipal water and wastewater treatment, adsorbents for stormwater treatment are barely regenerated. Therefore, the assessment of chemical leaching during disposal of spent adsorbents (e.g., landfilling) is of importance in case of secondary pollution. Chemical leaching from adsorbents at different situations can be rapidly estimated through implementation of appropriate standardized leaching tests. After passing the adsorption and leaching evaluations, the adsorbents can be recommended for use in stormwater treatment.

Besides adsorption and leaching properties, the application mode of adsorbents in stormwater treatment systems influences their optimal utilization. Simple addition to soil media in infrastructure can not provide a long-lasting treatment effect because the adsorbents would eventually become oversaturated. Instead, standalone filters or other innovative designs (e.g., adsorbent coated mulch chips) allow for periodic replacement of spent adsorbents, thus enabling a long-term constant treatment for polluted urban stormwater. In future studies, two questions rarely answered in previous investigations require special attention. One is how varied hydrological conditions (e.g., antecedent dry periods, precipitation durations, and precipitation patterns) and pollutant loadings at rainfall events affect the treatment performance of adsorbents. The other is what role microbial communities grown on the adsorbents play for the stormwater treatment. 
Acknowledgements We greatly appreciate the support from US Environmental Protection Agency (Grant Nos. SU836773 and SV839355).

Open Access This article is licensed under a Creative Commons Attribution 4.0 International License, which permits use, sharing, adaptation, distribution and reproduction in any medium or format, as long as you give appropriate credit to the original author(s) and the source, provide a link to the Creative Commons licence, and indicate if changes were made. The images or other third party material in this article are included in the article's Creative Commons licence, unless indicated otherwise in a credit line to the material. If material is not included in the article's Creative Commons licence and your intended use is not permitted by statutory regulation or exceeds the permitted use, you will need to obtain permission directly from the copyright holder. To view a copy of this licence, visit http://creativecommons.org/licenses/by/4.0/.

\section{References}

Ahmaruzzaman M (2010). A review on the utilization of fly ash. Progress in Energy and Combustion Science, 36(3): 327-363

Björklund K, Li L (2015). Evaluation of low-cost materials for sorption of hydrophobic organic pollutants in stormwater. Journal of Environmental Management, 159: 106-114

Chan K, Van Zwieten L, Meszaros I, Downie A, Joseph S (2007). Agronomic values of greenwaste biochar as a soil amendment. Soil Research (Collingwood, Vic.), 45(8): 629-634

Chavez R A, Brown G O, Storm D E (2013). Impact of variable hydraulic conductivity on bioretention cell performance and implications for construction standards. Journal of Hydraulic Engineering, 139(7): 707-715

Chen X, Yang L, Myneni S C, Deng Y (2019). Leaching of polycyclic aromatic hydrocarbons (PAHs) from sewage sludge-derived biochar. Chemical Engineering Journal, 373: 840-845

Chiang Y W, Ghyselbrecht K, Santos R M, Martens J A, Swennen R, Cappuyns V, Meesschaert B (2012). Adsorption of multi-heavy metals onto water treatment residuals: Sorption capacities and applications. Chemical Engineering Journal, 200-202: 405-415

Chiew F H, Mudgway L B, Duncan H P, Mcmahon T A (1997). Urban Stormwater Pollution, Industry Report. Clayton: Cooperative Research Centre for Catchment Hydrology Melbourne

Councell T B, Duckenfield K U, Landa E R, Callender E (2004). Tirewear particles as a source of zinc to the environment. Environmental Science \& Technology, 38(15): 4206-4214

Deng Y, Morris C, Rakshit S, Landa E, Punamiya P, Sarkar D (2016). Water treatment residuals and scrap tire rubber as green sorbents for removal of stormwater metals. Water Environment Research, 88(6): 500-509

Duranceau S J, Biscardi P G (2015). Comparing adsorptive media use for the direct treatment of phosphorous-impaired surface water. Journal of Environmental Engineering, 141(8): 04015012

Erickson A J, Gulliver J S, Weiss P T (2012). Capturing phosphates with iron enhanced sand filtration. Water Research, 46(9): 3032-3042

Genc-Fuhrman H, Mikkelsen P S, Ledin A (2007). Simultaneous removal of $\mathrm{As}, \mathrm{Cd}, \mathrm{Cr}, \mathrm{Cu}, \mathrm{Ni}$ and $\mathrm{Zn}$ from stormwater: Experimental comparison of 11 different sorbents. Water Research, 41(3): 591-602

Gunasekara A S, Donovan J A, Xing B (2000). Ground discarded tires remove naphthalene, toluene, and mercury from water. Chemosphere, 41(8): 1155-1160
Hale S E, Lehmann J, Rutherford D, Zimmerman A R, Bachmann R T, Shitumbanuma V, O'toole A, Sundqvist K L, Arp H P H, Cornelissen $\mathrm{G}$ (2012). Quantifying the total and bioavailable polycyclic aromatic hydrocarbons and dioxins in biochars. Environmental Science \& Technology, 46(5): 2830-2838

Harmayani K (2012). Adsorption of nutrients from stormwater using sawdust. International Journal of Environmental Sciences and Development, 3(2): 114-117

Hilber I, Blum F, Leifeld J, Schmidt H P, Bucheli T D (2012). Quantitative determination of PAHs in biochar: A prerequisite to ensure its quality and safe application. Journal of Agricultural and Food Chemistry, 60(12): 3042-3050

Jang A, Lee S, Seo Y, Kim K, Kim I, Bishop P (2007). Application of mulch for treating metals in urban runoff: batch and column test. Water Science and Technology, 55(1-2): 95-103

Jang A, Seo Y, Bishop P L (2005). The removal of heavy metals in urban runoff by sorption on mulch. Environmental Pollution, 133(1): 117127

Jin Q, Cui C, Chen H, Wu J, Hu J, Jing Hu, Xing X, Geng J, Wu Y (2019). Effective removal of $\mathrm{Cd}^{2+}$ and $\mathrm{Pb}^{2+}$ pollutants from wastewater by dielectrophoresis-assisted adsorption. Frontiers of Environmental Science \& Engineering, 13(2): 16

Kesraoui-Ouki S, Cheeseman C R, Perry R (1994). Natural zeolite utilisation in pollution control: A review of applications to metals' effluents. Journal of Chemical Technology and Biotechnology (Oxford, Oxfordshire), 59(2): 121-126

Knocke W, Hemphill L (1981). Mercury (II) sorption by waste rubber. Water Research, 15(2): 275-282

Lee J H, Bang K W (2000). Characterization of urban stormwater runoff. Water Research, 34(6): 1773-1780

Lehmann J, Joseph S (2015). Biochar for Environmental Management. New York: Routledge, 33-46

Li H, Dong X, Da Silva E B, de Oliveira L M, Chen Y, Ma L Q (2017). Mechanisms of metal sorption by biochars: biochar characteristics and modifications. Chemosphere, 178: 466-478

Li Z, Qiu Z, Yang J, Ma B, Lu S, Qin C (2018). Investigation of phosphate adsorption from an aqueous solution using spent fluid catalytic cracking catalyst containing lanthanum. Frontiers of Environmental Science \& Engineering, 12(6): 15

Liu J, Davis A P (2013). Phosphorus speciation and treatment using enhanced phosphorus removal bioretention. Environmental Science \& Technology, 48(1): 607-614

Liu Q, Wu L, Gorring M, Deng Y (2019). Aluminum-impregnated biochar for adsorption of arsenic (V) in urban stormwater runoff. Journal of Environmental Engineering, 145(4): 04019008

Makepeace D K, Smith D W, Stanley S J (1995). Urban stormwater quality: summary of contaminant data. Critical Reviews in Environmental Science and Technology, 25(2): 93-139

Melo L C, Puga A P, Coscione A R, Beesley L, Abreu C A, Camargo O A (2016). Sorption and desorption of cadmium and zinc in two tropical soils amended with sugarcane-straw-derived biochar. Journal of Soils and Sediments, 16(1): 226-234

Mohanty S K, Boehm A B (2014). Escherichia coli removal in biocharaugmented biofilter: effect of infiltration rate, initial bacterial concentration, biochar particle size, and presence of compost. Environmental Science \& Technology, 48(19): 11535-11542 
Mohanty S K, Cantrell K B, Nelson K L, Boehm A B (2014). Efficacy of biochar to remove Escherichia coli from stormwater under steady and intermittent flow. Water Research, 61: 288-296

Mwamulima T, Zhang X, Wang Y, Song S, Peng C (2018). Novel approach to control adsorbent aggregation: iron fixed bentonite-fly ash for Lead $(\mathrm{Pb})$ and Cadmium $(\mathrm{Cd})$ removal from aqueous media. Frontiers of Environmental Science \& Engineering, 12(2): 2

Nagar R, Sarkar D, Makris K C, Datta R (2010). Effect of solution chemistry on arsenic sorption by Fe-and Al-based drinking-water treatment residuals. Chemosphere, 78(8): 1028-1035

NJDEP (2004). New Jersey Stormwater Best management Practices Manual. Trenton: New Jersey Department of Environment Protection

Norris M J, Pulford I D, Haynes H, Dorea C C, Phoenix V R (2013). Treatment of heavy metals by iron oxide coated and natural gravel media in sustainable urban drainage systems. Water Science and Technology, 68(3): 674-680

NRC (2009). Urban Stormwater Management in the United States. Washington, DC: National Academies Press

O'Neill S W, Davis A P (2012a). Water treatment residual as a bioretention amendment for phosphorus. I: Evaluation studies. Journal of Environmental Engineering, 138(3): 318-327

O'Neill S W, Davis A P (2012b). Water treatment residual as a bioretention amendment for phosphorus. II: Long-term column studies. Journal of Environmental Engineering, 138(3): 328-336

Obropta C C, Kardos J S (2007). Review of urban stormwater quality models: Deterministic, stochastic, and hybrid approaches. Journal of the American Water Resources Association, 43(6): 1508-1523

Pitcher S, Slade R, Ward N (2004). Heavy metal removal from motorway stormwater using zeolites. Science of the Total Environment, 334: 161-166

Prakash P, SenGupta A K (2003). Selective coagulant recovery from water treatment plant residuals using donnan membrane process. Environmental Science \& Technology, 37(19): 4468-4474

Quilliam R S, Rangecroft S, Emmett B A, Deluca T H, Jones D L (2013). Is biochar a source or sink for polycyclic aromatic hydrocarbon (PAH) compounds in agricultural soils? Global Change Biology. Bioenergy, 5(2): 96-103

Reddy K R, Xie T, Dastgheibi S (2014a). Evaluation of biochar as a potential filter media for the removal of mixed contaminants from urban storm water runoff. Journal of Environmental Engineering, 140 (12): 04014043

Reddy K R, Xie T, Dastgheibi S (2014b). Nutrients removal from urban stormwater by different filter materials. Water, Air, and Soil Pollution, 225(1): 1778

Reddy K R, Xie T, Dastgheibi S (2014c). Removal of heavy metals from urban stormwater runoff using different filter materials. Journal of Environmental Chemical Engineering, 2(1): 282-292

Semerjian L (2010). Equilibrium and kinetics of cadmium adsorption from aqueous solutions using untreated Pinus halepensis sawdust. Journal of Hazardous Materials, 173(1-3): 236-242

Soleimanifar H, Deng Y, Barrett K, Feng H, Li X, Sarkar D (2019). Water treatment residual - coated wood mulch for addressing urban stormwater pollution. Water Environment Research, 91(6): 523-535

Soleimanifar H, Deng Y, Wu L, Sarkar D (2016). Water treatment residual (WTR)-coated wood mulch for alleviation of toxic metals and phosphorus from polluted urban stormwater runoff. Chemosphere, 154: 289-292

Tian J, Jin J, Chiu P C, Cha D K, Guo M, Imhoff P T (2019). A pilotscale, bi-layer bioretention system with biochar and zero-valent iron for enhanced nitrate removal from stormwater. Water Research, 148: 378-387

Turgeon A J, Mccarty L B, Christians N E (2009). Weed Control in Turf and Ornamentals. Upper Saddle River: Prentice Hall

Ulrich B A, Im E A, Werner D, Higgins C P (2015). Biochar and activated carbon for enhanced trace organic contaminant retention in stormwater infiltration systems. Environmental Science \& Technology, 49(10): 6222-6230

United-Nations (2018). The World's Cities (London, England). New York: United Nations

USEPA (2017). Leaching Environmental Assessment Framework (LEAF) How-To Guide. Washington, DC: USEPA

USEPA (2020). Basic Information: Scrap Tire. Washington, D.C.: USEPA

Wang S, Gao B, Zimmerman A R, Li Y, Ma L, Harris W G, Migliaccio K W (2015). Removal of arsenic by magnetic biochar prepared from pinewood and natural hematite. Bioresource Technology, 175: 391395

Wanielista M, Chang N B (2008). Alternative Stormwater Sorption Media for the Control of Nutrients. Orlando: Stormwater Management Academy, University of Central Florida

Wei G, Zhang J, Luo J, Xue H, Huang D, Cheng Z, Jiang X (2019). Nanoscale zero-valent iron supported on biochar for the highly efficient removal of nitrobenzene. Frontiers of Environmental Science \& Engineering, 13(4): 61

Wu P, Zhou Y S (2009). Simultaneous removal of coexistent heavy metals from simulated urban stormwater using four sorbents: A porous iron sorbent and its mixtures with zeolite and crystal gravel. Journal of Hazardous Materials, 168(2-3): 674-680

Xie T, Reddy K R, Wang C W, Yargicoglu E, Spokas K (2015). Characteristics and applications of biochar for environmental remediation: A review. Critical Reviews in Environmental Science and Technology, 45(9): 939-969

Zhang W, Brown G O, Storm D E, Zhang H (2008). Fly-ash-amended sand as filter media in bioretention cells to improve phosphorus removal. Water Environment Research, 80(6): 507-516

Ziyath A M, Mahbub P, Goonetilleke A, Adebajo M O, Kokot S, Oloyede A (2011). Influence of physical and chemical parameters on the treatment of heavy metals in polluted stormwater using zeolite: A review. Journal of Water Resource and Protection, 3(10): 758-767

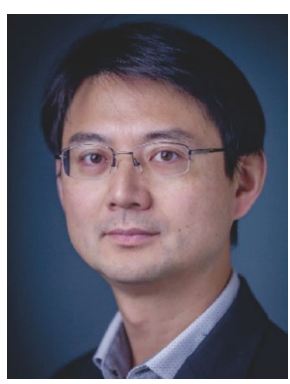

Yang Deng, Ph.D., P.E., is a Professor of Environmental Engineering at Montclair State University (New Jersey, USA). His research centers on innovative and sustainable water treatment technologies. Dr. Deng has authored or co-authored more than 120 peer-reviewed journal articles. He is the recipient of 2019 Superior Achievement Award from the American Academy of Environmental Engineers \& Scientists (AAEES).

Dr. Deng earned his B.S. and M.S. at Tongji University 
Front. Environ. Sci. Eng. 2020, 14(5): 83

(Shanghai, China) and his Ph.D. at the University of Miami (Florida, USA).

Dr. Deng presently serves as Associate Editor for Water Environment Research and Journal of Environmental Engineering-
$A S C E$, in addition to the Editor of Invited Reviews/Manuscripts for the Journal of Environmental Engineering-ASCE. He is also a member in the Editorial Board of Journal of Hazardous Materials and Chemical Engineering Journal Advances. 